\title{
Temporal changes in the characteristics of algae in Dianchi Lake, Yunnan Province, China
}

\author{
Ruixia SHEN $^{1 *}$, Chunyan TIAN ${ }^{1 *}$, Zhidan LIU (ه) ${ }^{1}$, Yuanhui ZHANG $(\bowtie)^{1,2}$, Baoming LI ${ }^{1}$, Haifeng LU ${ }^{1}$, \\ Na DUAN ${ }^{1}$ \\ 1 Laboratory of Environment-Enhancing Energy (E2E) and Key Laboratory of Agricultural Engineering in Structure and Environment, \\ Ministry of Agriculture, College of Water Resources and Civil Engineering, China Agricultural University, Beijing 100083, China \\ 2 Department of Agricultural and Biological Engineering, University of Illinois at Urbana-Champaign, Urbana, IL 61801, USA
}

\begin{abstract}
Algal blooms have become a worldwide environmental concern due to water eutrophication. Dianchi Lake in Yunnan Province, China is suffering from severe eutrophication and is listed in the Three Important Lakes Restoration Act of China. Hydrothermal liquefaction allows a promising and direct conversion of algal biomass into biocrude oil. In this study, algal samples were collected from Dianchi Lake after a separation procedure including dissolved air flotation with polyaluminum chloride and centrifugation during four months, April, June, August and October. The algal biochemical components varied over the period; lipids from $0.7 \%$ to $2.1 \%$ ash-free dry weight (afdw), protein from $20.9 \%$ to $33.4 \%$ afdw and ash from $36.6 \%$ to $45.2 \%$ dry weight. The algae in June had the highest lipid and protein concentrations, leading to a maximum biocrude oil yield of $24.3 \%$ afdw. Biodiversity analysis using pyrosequencing revealed different distributions of microbial communities, specifically Microcystis in April (89.0\%), June (63.7\%) and August (84.0\%), and Synechococcus in April (2.2\%), June (12.0\%) and August (1.0\%). This study demonstrated remarkable temporal changes in the biochemical composition and biodiversity of algae harvested from Dianchi Lake and changes in biocrude oil production potential.
\end{abstract}

Keywords algal blooms, temporal change, biochemical property, biodiversity, hydrothermal liquefaction

Received May 28, 2015; accepted July 19, 2015

Correspondences: zdliu@cau.edu.cn, yzhang1@illinois.edu

${ }^{*}$ These authors contribute equally to the work

\section{Introduction}

Eutrophication and the resulting algal blooms in waterways has received increasing attention worldwide ${ }^{[1]}$. Dianchi Lake, Yunnan Province, China, a $309 \mathrm{~km}^{2}$ reservoir at an altitude of $1886 \mathrm{~m}$, has suffered from algal blooms due to the eutrophication of water since the 1980s, and has recently been listed in the Three Important Lakes Restoration Act of China ${ }^{[2]}$. Algal blooms bring severe environmental problems and subsequently affect municipal water supply, aquaculture industries, the ecoenvironment and human health ${ }^{[3]}$. Mitigating the algal blooms in Dianchi Lake is not only a crucial challenge for the sustainable development of the local area, but is also significant for understanding eutrophication of lakes at high altitude. Hydrothermal liquefaction (HTL) is considered to be a potential alternative for algae biofuel production. In this process, wet algae are directly converted into biocrude oil regardless of the lipid content and drying process of the feedstock ${ }^{[4]}$. Algae biofuels have received increasing interest as next generation biofuels ${ }^{[5]}$.

One of the important factors determining the performance of algal HTL is the algal components and species $^{[5,6]}$. Recent studies indicate that biocrude oil yield is dependent on the organic components of algae rather than just the lipids ${ }^{[7,8]}$. In general, the significance of the biochemical components on the biocrude oil yield is ranked in the order of lipids $>$ proteins $>$ carbohydrates $^{[9,10]}$. However, high contents of ash or carbohydrates might negatively impact the production of biocrude oil from most algae species ${ }^{[5,10]}$. Algal biochemical composition is dependent on many factors, including algae species and the growing conditions ${ }^{[11]}$. Specifically, the biomass accumulation of algal blooms is influenced by nutrient input, temporal changes in the aquatic environment ${ }^{[12,13]}$, and even the harvest procedures ${ }^{[14]}$. Biodiver- 
sity analysis may provide physiological characterization of algal blooms and even their influence on dynamic changes in biochemical components and utilization ${ }^{[6]}$. Advances in molecular biology methods allow characterizing biodiversity without the need for complete study of microbial morphology or structure. Pyrosequencing is recognized as one of these technologies and it possesses the advantages of high repeatability, parallelism and automation ${ }^{[6]}$.

Therefore, understanding the biochemical composition and biodiversity of the harvested algal biomass from Dianchi Lake is an important precondition for its conversion into sustainable biocrude oil through HTL.

In this study, algal samples in Dianchi Lake were collected from a large-scale algal blooms harvest facility in four representative months: August, 2012; October, 2012; April, 2013; June, 2013. The purposes of this study were: (1) investigate temporal changes in the biochemical components and microbial diversity of algal samples using pyrosequencing; (2) analyze the relationship between biochemical components and biodiversity; (3) determine the effect of the algae properties on biocrude oil production using HTL.

\section{Materials and methods}

\subsection{Feedstock preparation}

Algal samples were collected from a large-scale algal blooms harvest facility, Dianchi Algae-Water Separation Station, Kunming, China. The station runs from April to November when algal blooms take place at a high frequency $^{[15,16]}$. As shown in, the main procedure for harvesting algal blooms included dissolved air flotation using polyaluminum chloride (PAC) as the coagulant, slurry regulation, and centrifugation with a cationic organic polymer as the coagulant. After centrifugation (Fig. 1), the dewatered algal slurry was freeze-dried and stored at $-20^{\circ} \mathrm{C}$ prior to analysis. Algal samples were collected during four representative months: August, 2012; October, 2012; April, 2013; June, 2013, in order to study the influence of temporal changes on algal properties and HTL conversion. The properties of the harvested algae after such separation procedures might be different from those of algae collected directly from the lake. The reason for using harvested algae was to generate data applicable to commercial production of biofuels from algal blooms.

\subsection{Analysis of algal biochemical components and hydrothermal liquefaction experiments}

Algal components were analyzed according to standard methods ${ }^{[8]}$, including proximate analysis, chemical analysis, and ultimate analysis. Proximate analysis was carried out on a dry weight (dw). Moisture content was measured through drying the sample at $105^{\circ} \mathrm{C}$ to a constant weight. Volatile matter content was determined by pyrolysis at $950 \pm 20^{\circ} \mathrm{C}$ for $7 \mathrm{~min}$. Ash content was measured by drying the samples at $575^{\circ} \mathrm{C}$ for more than $4 \mathrm{~h}$, and the components of algal ash were determined using an X-ray fluorescence analyzer (XRF-1800, Shimadzu Company, Tokyo, Japan). The higher heating value was determined using an oxygen bomb calorimeter (Model 6200, Parr Instrument Co., Moline, Illinois, USA).

Chemical analysis was performed on ash-free dry weight (afdw). Crude lipid content was determined using Soxhlet extraction. Protein content was measured using a Kjeldahl analyzer with the Kjeldahl-N to protein factor of $5.95^{[17]}$.

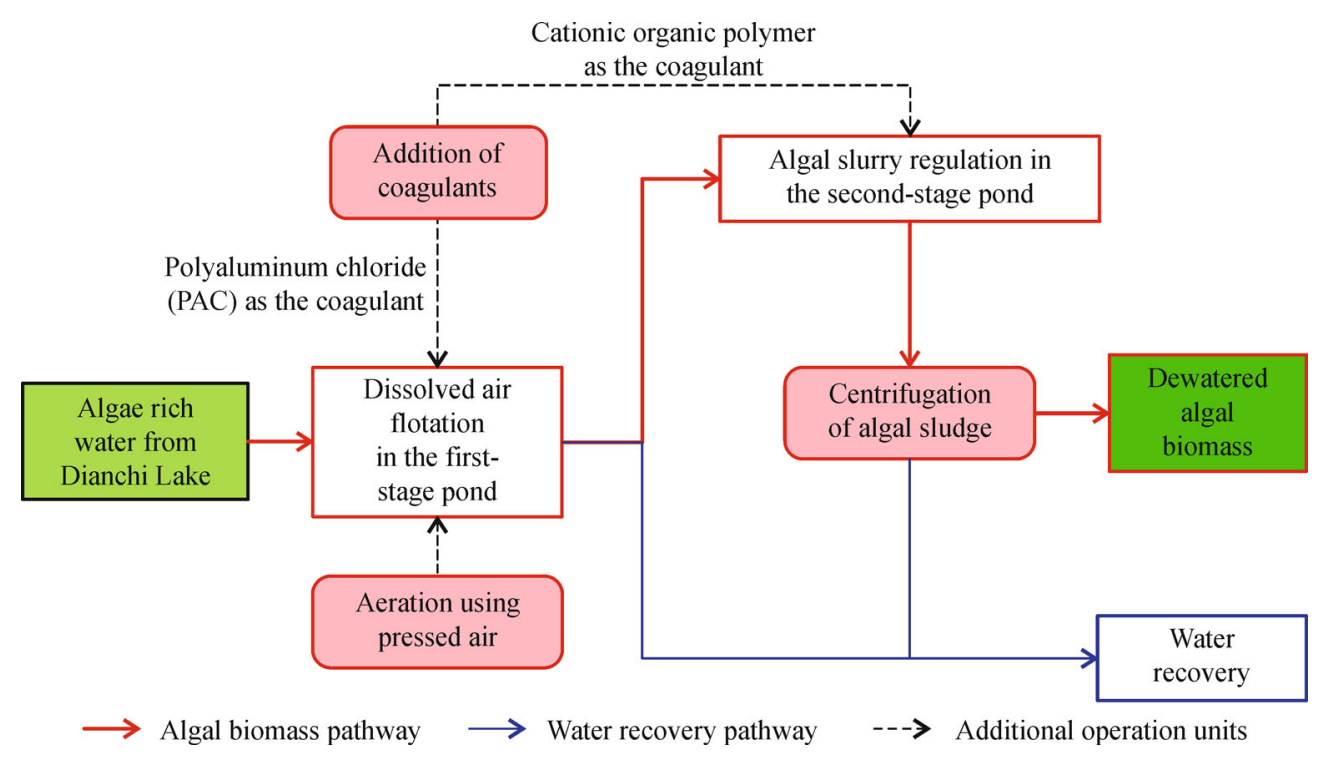

Fig. 1 Flow diagram of the harvest and separation process for algal samples from Dianchi Lake with temporal changes. The harvesting procedure mainly included dissolved air flotation, slurry regulation and centrifugation. 
Crude fiber content was determined using a fiber analyzer (Model A220, ANKOM Technology Corporation, NY, USA). Ultimate analysis (specially organic elements) was performed using an element analyzer (Vario MICRO Cube, Elementar Analysensysteme GmbH, Donaustraße, Germany). All measurements were performed in triplicate, and the presented values are the mean values of the three trials.

HTL experiments were carried out in a $100 \mathrm{~mL}$ batch reactor (Model 4593, Parr Instruments Co., Moline, IL) with a total solid content of $20 \%$, an initial head-space pressure of $3 \mathrm{MPa}$, a holding temperature of $300^{\circ} \mathrm{C}$, and a retention time of $60 \mathrm{~min}$, as previously described ${ }^{[18]}$. After HTL, the gases were first released and the products were divided into aqueous products and raw oil. The raw oil contained solid residue and biocrude oil. The biocrude oil was recovered through acetone extraction for $30 \mathrm{~min}$ assisted with an ultrasonic generator, and the solid residue was separated using vacuum filtration. The biocrude oil was finally dried in a vacuum oven $\left(70^{\circ} \mathrm{C}, 20 \mathrm{kPa}\right)$ for more than $10 \mathrm{~h}$ until it reached a constant weight prior to analysis. The biocrude oil yield was calculated using the following formula:

$$
\begin{aligned}
& \text { Biocrude oil yield (afdw\%) } \\
= & \frac{\text { Mass of biocrude oil }}{\text { Mass of ash free dry algae }} \times 100 \%
\end{aligned}
$$

\subsection{Biodiversity analysis by pyrosequencing}

The biodiversity of algal samples was analyzed by pyrosequencing. The DNA of the algal samples was first extracted and amplified using a GeneAmp ${ }^{\mathbb{R}}$ PCR System (Model 9700, ABI company, USA) with one cycle at $98^{\circ} \mathrm{C}$ ( $3 \mathrm{~min}$ ), followed by 45 cycles consisting of $98^{\circ} \mathrm{C}$ for $45 \mathrm{~s}$, $45^{\circ} \mathrm{C}$ for $45 \mathrm{~s}$, and $72^{\circ} \mathrm{C}$ for $1 \mathrm{~min}$, and finally $72^{\circ} \mathrm{C}$ for $5 \mathrm{~min}$. In the procedure of genomic DNA pyrosequencing, a high-throughput pyrosequencing platforms were chosen (Roche 454 Genome Sequencer FLX + ). Specific primers of algal samples were designed for PCR amplification based on a 16S rRNA gene ${ }^{[19]}$, and the details as below: CYA781a (5'-GAC TAC TGG GGT ATC TAA TCC CAT T-3'), CYA781b (5'-GAC TAC AGG GGT ATC TAA TCC CTT T-3'), and CYA359F (5'-GGG GAA TYT TCC GCA ATG GG-3'). The preliminary experiment showed that the DNA fragment size (about $500 \mathrm{bp}$ ), extracted from algae and amplified by PCR, was in accord with the demands of pyrosequencing (400 to $700 \mathrm{bp}$ ). Operational taxonomic units (OTU), rarefaction curves, and biodiversity indices were employed in order to estimate the abundance and biodiversity of algal species ${ }^{[20]}$. The calculation of the relative abundance was based on all available sequences. Rarefaction curves of all samples were at a $97 \%$ similarity level. A Quantitative Insights into Microbial Ecology
Platform (Shanghai Meiji Company, China) with a RDP classifier was used for taxonomy analysis.

The PCR fragments of the algal sample in October were too weak to be detected after repeated experiments. Therefore, the sample was not used for subsequent pyrosequencing analysis. It was believed that the algal cells collected in October were partly damaged during the harvesting process as shown in Fig. $1^{[21]}$.

\section{Results and discussion}

3.1 Temporal changes in biochemical compositions of algal samples and biocrude oil production

The freeze-dried algae samples had an average total solids content of about $90 \%$ and an average ash content of $40 \%$ (Table 1). The biochemical analysis (Table 1 ) shows that algae had very low lipid contents $(0.7 \%-2.1 \%$ afdw) and high carbohydrate contents $(64.6 \%-78.3 \%$ afdw). Note that the term "carbohydrates content" was classified as crude fiber and non-fibrous carbohydrates ${ }^{[8,10]}$. Compared to the algae directly collected from Dianchi Lake ${ }^{[22]}$, the algal samples in this study had relatively high ash contents $(36.6 \%-45.2 \%$ afdw), the reason for this is probably the addition of coagulants which contains abundant $\mathrm{Al}$ in the harvest procedure (Fig. 1). The addition of PAC as the coagulant during algal separation contributed to the ash content. Specifically, the August algae sample had the highest ash content $(45.2 \% \mathrm{dw})$ and the highest crude fiber content ( $25.9 \%$ afdw).

The treatment of harvested algal blooms through HTL shows promise. The moisture of harvested algae is already about $80 \%-87 \%$, which is specifically suitable for HTL ${ }^{[4]}$ without an additional energy-intensive drying process. In addition, the low-lipid content $(0.7 \%-2.1 \%$ afdw) of harvested algae may not be a problem for HTL since its total organic components can be fully converted into biocrude oil through $\mathrm{HTL}^{[8]}$. However, the achieved biocrude oil yields (14.5\%-24.3\% afdw) of all algal samples were relatively low, due to their high ash and carbohydrate contents ${ }^{[5,10]}$. The element composition of the ash is discussed below. The biocrude oil yields (14.5\%-24.3\% afdw) through HTL were higher than the lipid contents of the feedstocks $(0.7 \%-2.1 \%$ afdw), indicating that some non-lipid organic components of algae were converted into biocrude oil ${ }^{[8]}$. Proximate analysis indicated that the biocrude oil yields from different algal samples were positively correlated with fixed carbon (Table 1). Specifically, the highest biocrude oil conversion was from the June sample, due to its highest content of lipids ( $2.1 \% \mathrm{afdw})$ and proteins $(33.4 \%$ afdw).

These results reveal that biochemical components of algal samples change with time, leading to different HTL biocrude oil yields. It is evident that the biocrude oil yield 
Table 1 Characteristics of the harvested algal samples from Dianchi Lake and their biocrude oil yields using HTL

\begin{tabular}{|c|c|c|c|c|}
\hline Sampling months & April & June & August & October \\
\hline \multicolumn{5}{|l|}{ Proximate Analysis } \\
\hline Moisture $/ \%$ & $9.0 \pm 0.3$ & $8.9 \pm 0.4$ & $8.5 \pm 0.1$ & $13.0 \pm 0.1$ \\
\hline Volatile matter $\mathrm{b} / \%$ & $45.4 \pm 0.0$ & $42.5 \pm 0.1$ & $44.4 \pm 1.8$ & $45.4 \pm 0.1$ \\
\hline Ash content $\mathrm{b} / \%$ & $41.0 \pm 0.4$ & $36.6 \pm 0.1$ & $45.2 \pm 0.2$ & $40.9 \pm 0.1$ \\
\hline Fixed carbon $\mathrm{b} / \%$ & $13.6 \pm 0.1$ & $20.9 \pm 0.2$ & $10.4 \pm 1.7$ & $13.7 \pm 0.2$ \\
\hline $\mathrm{HHV}^{*} /\left(\mathrm{MJ} \cdot \mathrm{kg}^{-1}\right)$ & $9.3 \pm 0.1$ & $11.2 \pm 0.2$ & $7.2 \pm 0.1$ & $8.0 \pm 0.0$ \\
\hline \multicolumn{5}{|l|}{ Chemical Analysis ${ }^{c} / \%$} \\
\hline Crude lipids & $1.0 \pm 0.4$ & $2.1 \pm 1.4$ & $0.8 \pm 0.5$ & $0.7 \pm 0.4$ \\
\hline Crude proteins & $24.6 \pm 0.2$ & $33.4 \pm 0.2$ & $20.9 \pm 0.1$ & $22.6 \pm 0.7$ \\
\hline Crude fiber & $12.8 \pm 6.4$ & $13.9 \pm 0.1$ & $25.9 \pm 5.3$ & $19.2 \pm 3.9$ \\
\hline Non-fibrous carbohydrates ${ }^{\mathrm{c}, * / \%}$ & $61.6 \pm 4.2$ & $50.6 \pm 1.3$ & $52.4 \pm 4.3$ & $57.6 \pm 3.0$ \\
\hline \multicolumn{5}{|l|}{ HTL Biocrude Oil $/ \%$} \\
\hline Biocrude oil yields & $16.5 \pm 1.0$ & $24.3 \pm 1.7$ & $14.5 \pm 0.3$ & $16.5 \pm 0.3$ \\
\hline
\end{tabular}

Note: ${ }^{\text {a }}$ Percentage based on weight; ${ }^{\mathrm{b}}$ percentage based on dry weight; ${ }^{\mathrm{c}}$ percentage based on ash free dry weight. $*$ Calculated by differences. HHV, higher heating value.

from algal biomass is affected by its biochemical components ${ }^{[10]}$. The biochemical compositions of these harvested algal samples depend on many conditions, including nutrients input, the changing hydrological/ meteorological environment ${ }^{[23,24]}$, and even the harvesting procedure of the algal samples ${ }^{[14]}$. Therefore, the biodiversity analysis may provide more biological information to help explain the changes of biochemical components with temporal changes.

\subsection{Analysis of algal diversities using pyrosequencing}

The richness of algal species was calculated through analysis of the OTU obtained from the rarefaction curves (Fig. 2). The number of OTU increased with the depth of sequencing. The rarefaction curve tended to be gentle, suggesting a rational quantity of sequence data and the accuracy of the OTU analysis. The sample in June had the maximum of 50 OTU (Table 2), indicating that the biggest species richness of cyanobacteria occurred in June. In the same way, this result was confirmed by Ace index (52) and Chao index (51), which were both the estimated value of OTU. In addition, the biodiversity of algal samples was analyzed using both Shannon and Simpson indices (Table 2). The sample in June had the highest Shannon (1.84) and the lowest Simpson index (0.23), which supported the finding that the algal sample in June contained an overwhelming superiority in microbial diversity. The number of OTU and the overlaps in the venn chart (Fig. 3) further illustrate the relationships among algal samples. There were 36 similar OTUs comparing the samples in April and June, higher than the overlaps between June and August (32) and those between April and August (29). In addition, there were 27 similar
OTU observed among samples from April, June, and August. In comparison to the algal sample in June, those in April and October had very similar biochemical properties as well as nearly identical biocrude oil yields.

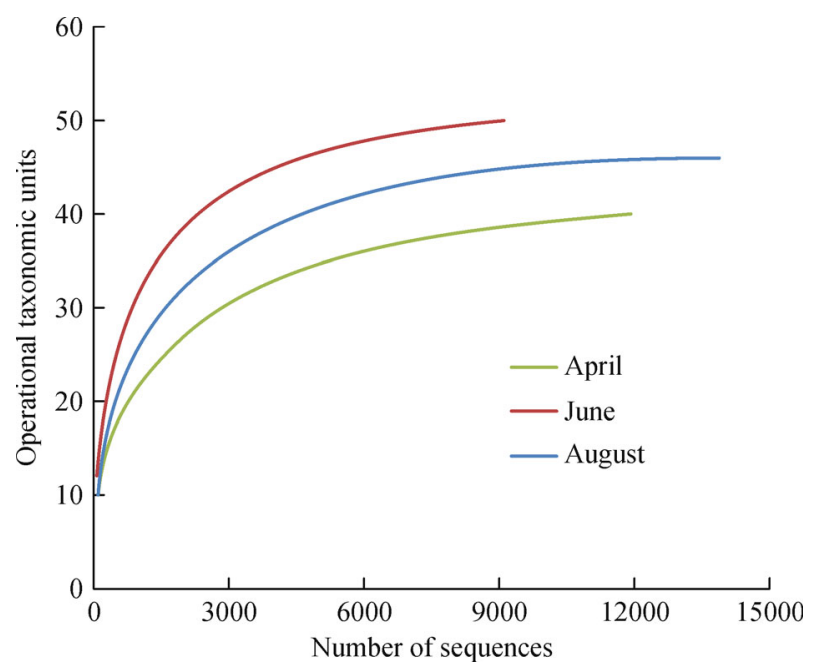

Fig. 2 Rarefaction curves of the harvested algal samples from Dianchi Lake at three sampling times, April, June and August. The curves of all samples were at a $97 \%$ similarity level.

Algal samples had different colors over time (Fig. 4a), which probably resulted from the changes in the biodiversity between the sampling times. To compare the phylogenetic changes in the microbial communities in the different months, the qualified reads were classified into 6 different levels, including phylum, class, order, family, genus and species. Fig. 4 shows the genus and order level classification of the microbial communities. Fourteen 
Table 2 Biodiversity analysis of the harvested algal samples from Dianchi Lake with temporal changes

\begin{tabular}{lcccccc}
\hline \multirow{2}{*}{ Sampling months } & \multirow{2}{*}{ Reads } & \multicolumn{5}{c}{ Similarity level = 0.97 } \\
\cline { 3 - 7 } & & OTU & Ace & Chao & Shannon & Simpson \\
\hline April & 11912 & 40 & 43 & 43 & 1.39 & 0.36 \\
June & 9078 & 50 & 52 & 51 & 1.84 & 0.23 \\
August & 13880 & 46 & 46 & 46 & 1.45 & 0.34 \\
\hline
\end{tabular}

Note: OUT, operational taxonomic units.

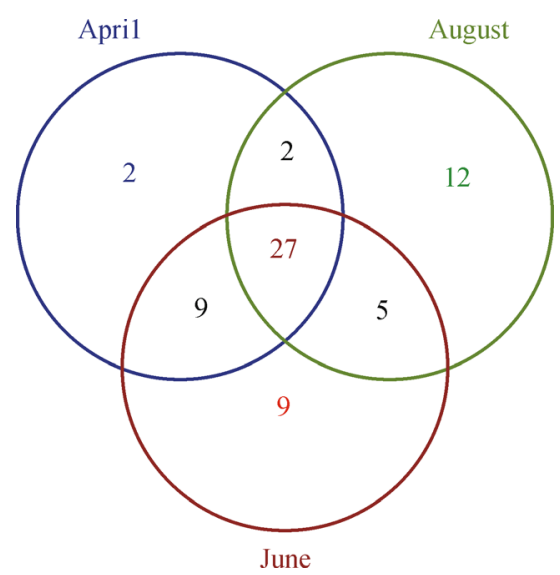

Fig. 3 Venn diagram for the harvested algal samples from Dianchi Lake at three sampling times, April, June and August. The numbers represents operational taxonomic units (OTU). The number of OTU and their overlaps between algal samples from different sampling times are indicated.

orders were detected, where Subsection I reached up to $95.0 \% \pm 0.2 \%$ of total reads. Specifically, the sample in April had lower diversity ( 7 orders) than those in June (11 orders) or August (10 orders) (Fig. 4b). The classification to genus provided detailed information about the microbial communities in the algal samples (Fig. 4c). Twenty two genera were detected in total, including Microcystis, Synechococcus, Anabaena, Blastopirellula, Brevundimonas, Erysipelothrix, Gleocapsa, Gloeothece, Pirellula and Planktothrix. The heatmap chart at the genus level further compared the composite structure of three algal samples, where different colors represented respective relative abundances of different samples (Fig. 5). This comparison showed 13 genera were detected in algal samples in April, 18 in June, and 15 in August. In particular, Microcystis and Synechococcus were two major genera in the algal samples. Microcystis held an overwhelming majority in April (89.00\%), June (63.70\%) and August (84.00\%), which was consistent with the previous morphological observations of algae in Dianchi Lake using scanning electron microscopy ${ }^{[25]}$. Synechococcus was found to be the second most dominant group, which reached about $12 \%$ in August. By comparison, Blastopirellula and Brevundimonas were only detected in August, and Pirellula only in June (Fig. 5).

These results reveal that there were possible correlations between community distribution, as determined by pyrosequencing, and time of sampling. The abundance of Microcystis was $89.00 \%$ in April, but only $63.70 \%$ in June. In contrast, the abundance of Synechococcus was only $2.20 \%$ in April and $12.00 \%$ in June. The unclassified genera were up to $20.50 \%$ in June. Thus, it is reasonable to conclude that the phylogenetic difference have caused the color differences among the samples. Compared to the samples in June, algal samples in August had a 21.00\% increase of Microcystis but a $2.00 \%$ decrease of Synechococcus. The various microbial communities in three sampling months may be due to different environmental conditions, such as water temperature and nutrient input ${ }^{[12,13,26,27]}$. According to a previous study ${ }^{[28]}$, the average water temperature in Dianchi Lake was about $17.5^{\circ} \mathrm{C}$ in April, $24.0^{\circ} \mathrm{C}$ in June and $24.3^{\circ} \mathrm{C}$ in August, which may affect the algae growth and community composition. The different contents of Microcystis can be explained by the competing relationships with other algae species ${ }^{[29]}$. Microbial communities analyzed in this study were slightly different from those communities reported directly from Dianchi Lake $^{[25,28]}$, probably due to the influence of the harvesting procedure (Fig. 1).

Another notable point is the relationship between the microbial communities of the algal samples and their biochemical components. As discussed previously for Table 1, the sample in June had the highest protein (33.4\% afdw) and lipid (2.1\% afdw) contents, which may be caused by its specific microbial distribution: the lowest content of Microcystis and the highest content of Synechococcus among all algae samples. Microcystis may result in the highest content of carbohydrates $(64.5 \%-78.3 \%)$, which further negatively impacts on biocrude oil production ${ }^{[10]}$. Thus, the various algal diversities in different sampling months may provide possible clues for the differences in the biochemical compositions, which further impacts on HTL strategies for biocrude oil production, such as operating conditions and ash removal.

\subsection{Elements analysis of algal samples and temporal changes}

\subsubsection{Organic elements analysis}

Table 3 gives the element analysis data for the algal 

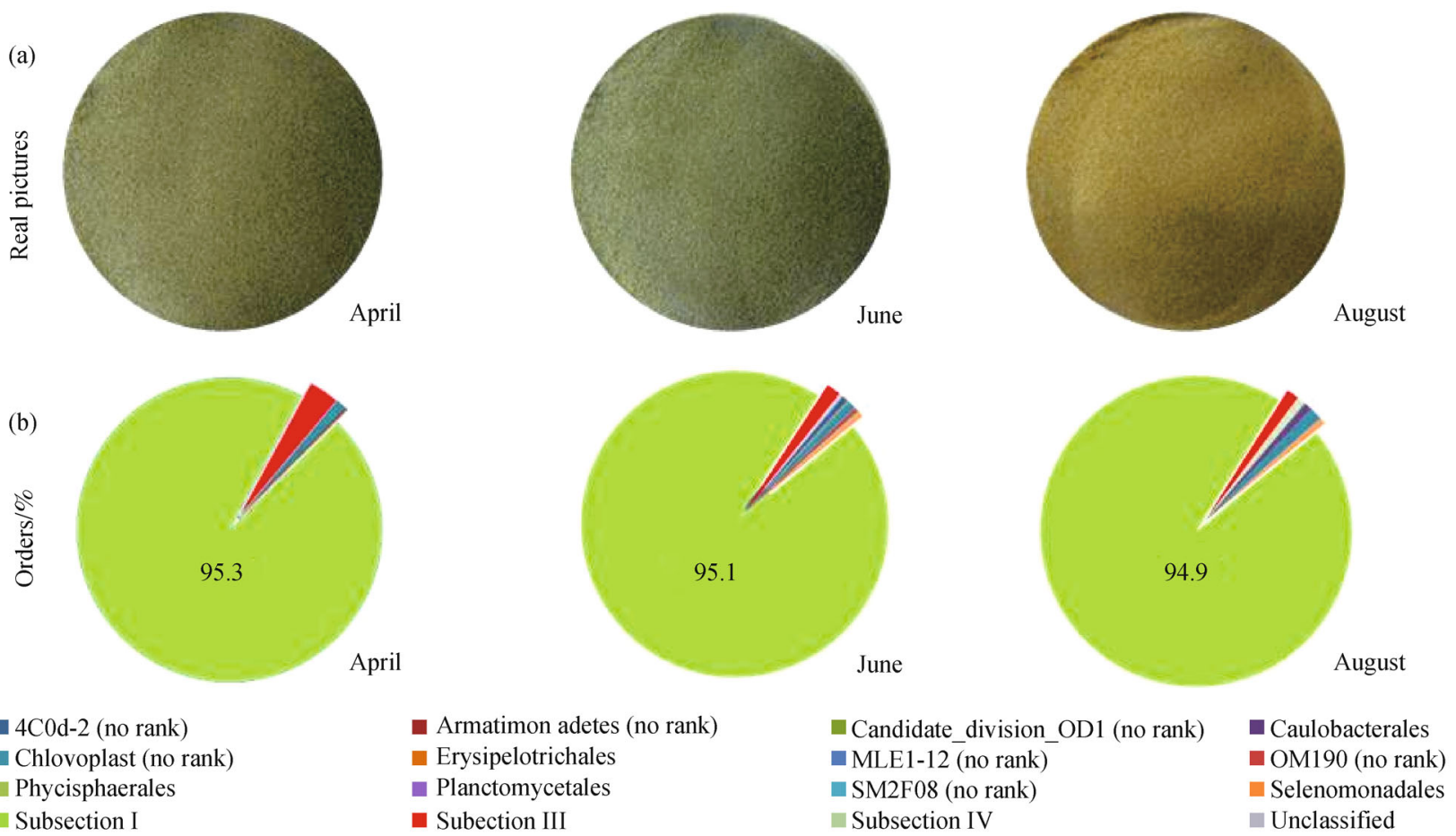

- 4C0d-2 (no rank)

- Chlovoplast (no rank)

Phycisphaerales

Subsection I
- Armatimon adetes (no rank)

- Erysipelotrichales

- Planctomycetales

- Subection III
- Candidate_division_OD1 (no rank)

- MLE1-12 (no rank)

- SM2F08 (no rank)

Subsection IV
OM190 (no rank)

Unclassified

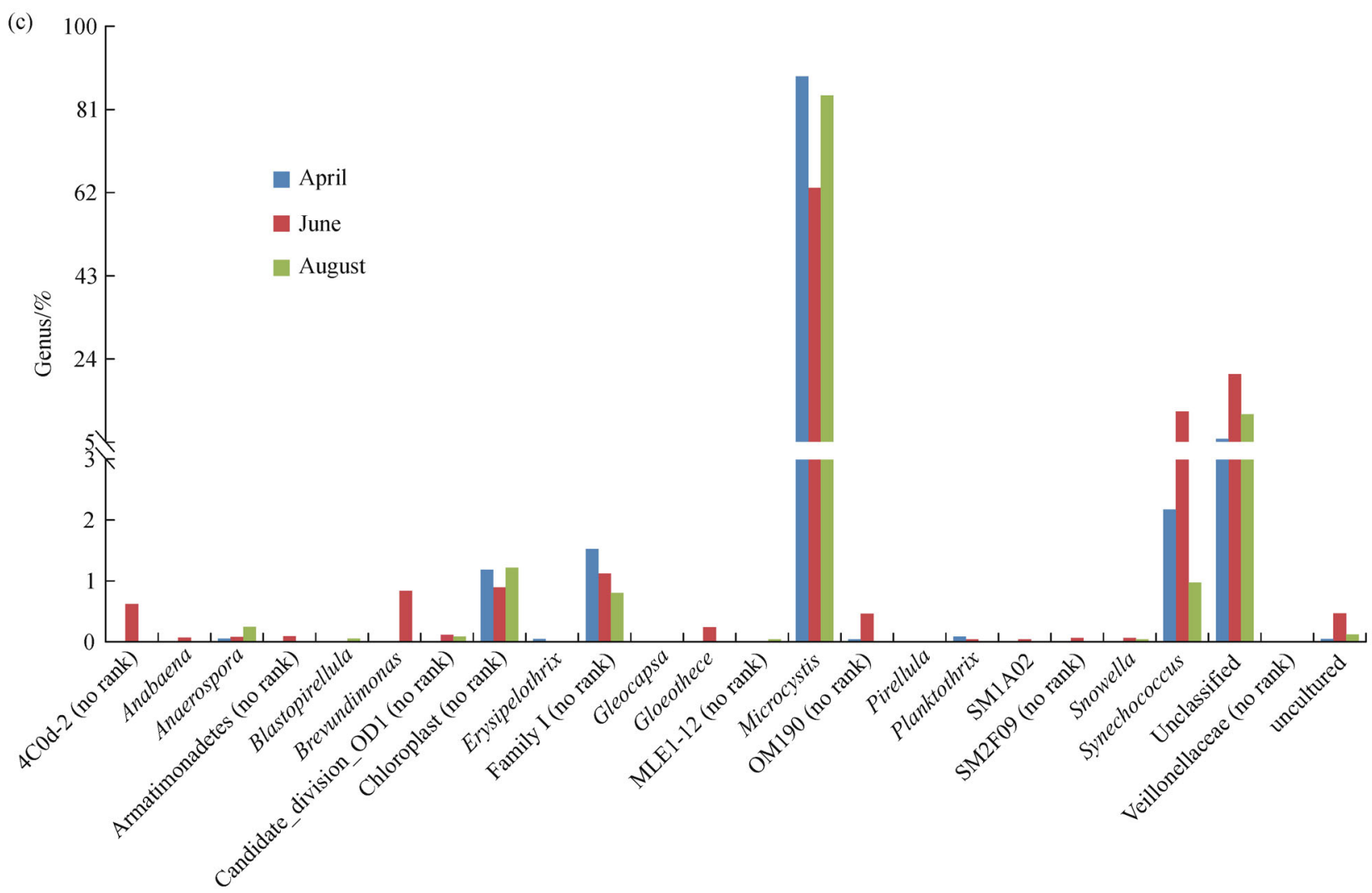

Fig. 4 Pictures of algal samples (a) and taxonomic classification of pyrosequencing for the microbial communities of the harvested algal samples from Dianchi Lake at three sampling times, April, June and August for orders (b) and genera (c). No rank, indicates no scientific names in current taxonomic database; Unclassified, represents the communities with a classification score below 0.7 . 


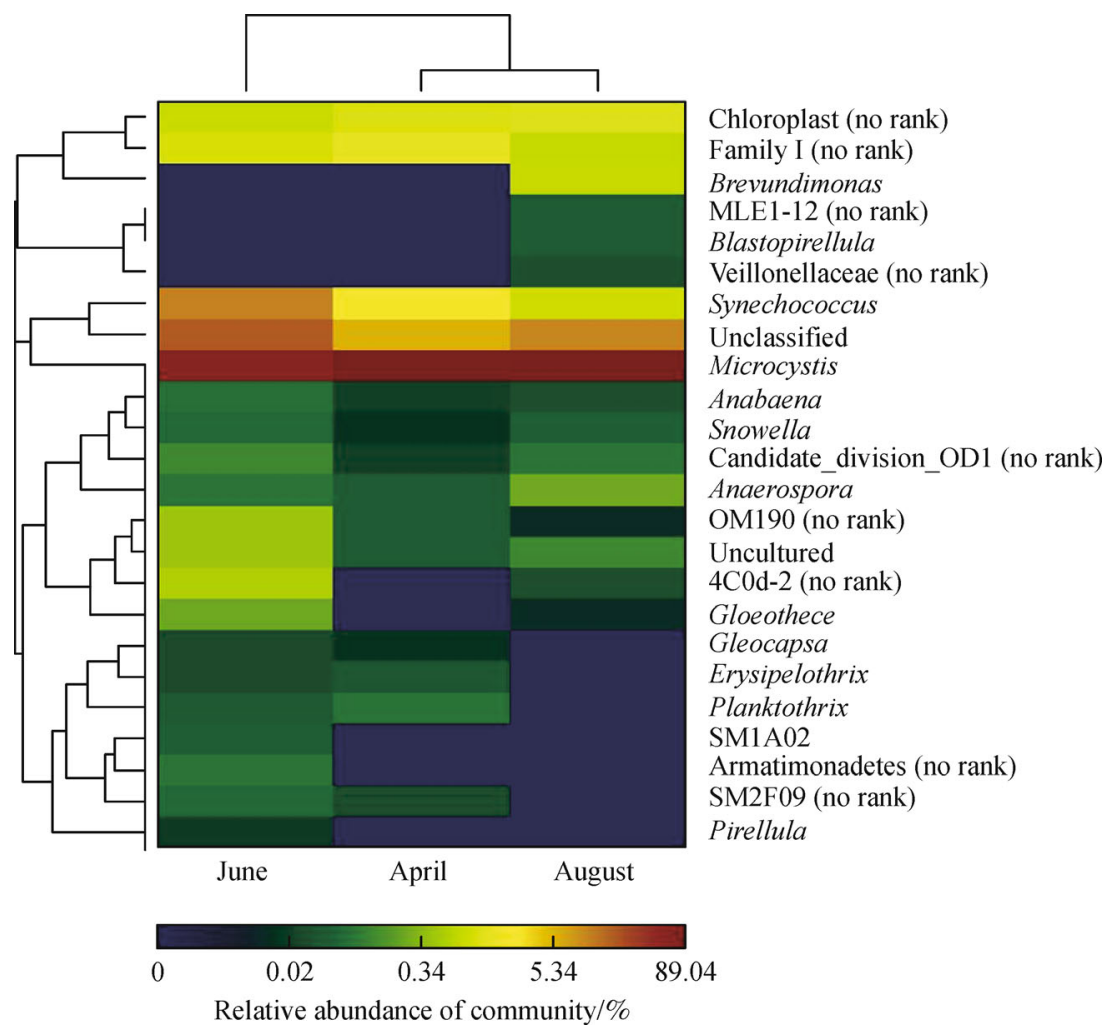

Fig. 5 Heatmap of the harvested algal samples from Dianchi Lake at three sampling times, April, June and August. The phylogenetic tree reveals the similarities between different algal samples from three sampling times.

samples. Algal samples were composed of approximately $20.320 \%-27.470 \%$ dw C, $4.210 \%-4.540 \%$ dw H, $2.583 \%-4.768 \% \mathrm{dw} \mathrm{N}$, and $27.360 \%-28.260 \% \mathrm{dw} \mathrm{O}$. Lipids and carbohydrates mainly consisted of $\mathrm{C}$ and $\mathrm{H}$, whereas proteins had high nitrogen contents. The highest $\mathrm{N}$ content of the sample in June $(4.768 \% \mathrm{dw})$ was consistent with its highest content of crude proteins (33.4\% afdw). C, N and P, were found to influence significantly the compositions of algal biomass in Dianchi Lake ${ }^{[26]}$, which may further affect the performance of algal $\mathrm{HTL}^{[8,30]}$.

\subsubsection{Inorganic element analysis}

Table 3 shows the composition of elements in the algal ash. Algal ash mainly consisted of oxides, phosphates, and sulfates with high oxygen contents. Inorganic forms of $\mathrm{C}$ and $\mathrm{N}$ were not detected in the ash. As with $\mathrm{N}$ content in the organic analysis, $\mathrm{P}$ content for the sample was the highest $(0.330 \%, \mathrm{dw})$ in June.

The most abundant inorganic elements in the algal samples (Table 3), included Al $(8.385 \%-13.573 \% \mathrm{dw})$, Fe $(3.439 \%-5.028 \% \mathrm{dw}), \mathrm{Si}(2.912 \%-3.206 \% \mathrm{dw})$, and $\mathrm{Ca}(2.912 \%-3.180 \% \mathrm{dw})$. In particular, the sample in August with the highest ash content $(45.2 \% \mathrm{dw})$ (Table 1$)$ had the highest content of $\mathrm{Al}(13.573 \% \mathrm{dw})$ and $\mathrm{Fe}(5.028 \% \mathrm{dw})$ and the lowest content of $\mathrm{Ca}(2.912 \%$ dw), opposite to the samples in June. According to the data of the surface sediments in Dianchi Lake ${ }^{[31,32]}$, sediments are rich in $\mathrm{P}, \mathrm{Ca}, \mathrm{Al}, \mathrm{Fe}, \mathrm{K}, \mathrm{Ti}, \mathrm{Cu}, \mathrm{Co}, \mathrm{Ni}, \mathrm{Pb}, \mathrm{Zn}, \mathrm{Cd}, \mathrm{Cr}$ and $\mathrm{Zr}$. The contents of the above elements in sediments all increased from the bottom to the top of sediments, especially for $\mathrm{P}$ and $\mathrm{Ca}$.

The inorganic element composition of algal ash was influenced by many factors, including environmental conditions ${ }^{[23,26-28]}$, the absorption capability of algae species $^{[13,33]}$, and the harvest procedure (Fig. 1). Environmental conditions affected algae growth and further influence its composition ${ }^{[13,27]}$. The high content of $\mathrm{Al}$ in the algal ash was largely attributed to Al-rich PAC used as the coagulant during the harvest process ${ }^{[18,34]}$, which caused the difference in ash content between natural algae $^{[22]}$ and harvested algae in this study. Fe plays a critical role in algal blooms ${ }^{[1,35]}$. Algae need moderate contents of $\mathrm{Al}, \mathrm{Fe}, \mathrm{Ca}, \mathrm{K}, \mathrm{Na}, \mathrm{Mg}, \mathrm{Mn}$ and $\mathrm{Zn}$ for their growth $^{[11]}$. In addition, natural algae might grow with high content of metals ${ }^{[11,36]}$. The dominant algal species detected in this study, Microcystis and Synechococcus ${ }^{[36]}$ have different absorption abilities for $\mathrm{Fe}$, leading to different Fe contents (Table 3 ). As discussed above, the high ash content may negatively influence the performance of algal HTL ${ }^{[4,18]}$. Further study is be undertaken on ash removal from algal samples from Dianchi Lake and its influence on algal HTL. 
Table 3 Analysis of the elements in harvested algal samples and algal ash

\begin{tabular}{|c|c|c|c|c|}
\hline Sampling months & April & June & August & October \\
\hline \multicolumn{5}{|c|}{$\overline{\text { Ultimate/organic elements analysis of algal samples }{ }^{a} / \%}$} \\
\hline Carbon $(\mathrm{C})$ & 22.600 & 27.470 & 20.320 & 23.330 \\
\hline Hydrogen $(\mathrm{H})$ & 4.290 & 4.210 & 4.370 & 4.540 \\
\hline Nitrogen $(\mathrm{N})$ & 3.264 & 4.768 & 2.583 & 3.003 \\
\hline Oxygen $(\mathrm{O})$ & 28.200 & 27.360 & 27.970 & 28.260 \\
\hline \multicolumn{5}{|c|}{ Inorganic elements analysis of the algal ash ${ }^{a} / \%$} \\
\hline Aluminum (Al) & 10.156 & 8.385 & 13.573 & 11.378 \\
\hline iron $(\mathrm{Fe})$ & 3.913 & 3.439 & 5.028 & 4.676 \\
\hline Silicon (Si) & 3.206 & 2.912 & 2.912 & 3.090 \\
\hline Calcium (Ca) & 2.936 & 3.120 & 1.252 & 1.533 \\
\hline Titanium (Ti) & 0.356 & 0.257 & 0.338 & 0.327 \\
\hline Potassium (K) & 0.268 & 0.310 & 0.226 & 0.281 \\
\hline Magnesium (Mg) & 0.247 & 0.444 & 0.156 & 0.178 \\
\hline Manganum (Mn) & 0.047 & 0.043 & 0.041 & 0.054 \\
\hline Sodium (Na) & 0.042 & 0.044 & 0.066 & 0.063 \\
\hline Zirconium (Zr) & 0.020 & 0.014 & 0.020 & 0.019 \\
\hline Chromium (Cr) & 0.018 & 0.015 & 0.021 & 0.019 \\
\hline Strontium (Sr) & 0.011 & 0.013 & 0.006 & 0.009 \\
\hline Zincum (Zn) & 0.009 & 0.010 & 0.009 & 0.009 \\
\hline Gallium (Ga) & 0.005 & 0.004 & 0.006 & 0.005 \\
\hline Copper $(\mathrm{Cu})$ & 0.004 & 0.003 & 0.004 & 0.004 \\
\hline Niccolum (Ni) & 0.004 & 0.003 & 0.004 & 0.004 \\
\hline Yttrium (Y) & 0.002 & 0.003 & 0.003 & 0.003 \\
\hline Oxygen $^{\mathrm{b}}(\mathrm{O})$ & 19.171 & 16.956 & 21.048 & 18.766 \\
\hline Sulfur (S) & 0.318 & 0.218 & 0.319 & 0.289 \\
\hline Phosphorus (P) & 0.246 & 0.330 & 0.203 & 0.220 \\
\hline Chlorine $(\mathrm{Cl})$ & 0.035 & 0.026 & ND & ND \\
\hline Bromine (Br) & 0.003 & 0.003 & ND & ND \\
\hline
\end{tabular}

Note: ${ }^{\text {a }}$ Percentage of dry weight; ${ }^{\mathrm{b}}$ oxygen in the algal ash is present in the inorganic form. ND, not detected.

\section{Conclusions}

This study demonstrates that time of sampling had significant effects on the biochemical composition, the biodiversity of the harvested algae in Dianchi Lake and even the biocrude oil yield. In particular, algal samples in June had a significantly different distribution of microbial communities, the highest contents of proteins and lipids, and the lowest content of ash, eventually leading to the highest biocrude oil yield of $24.3 \%$ afdw. This relatively low oil yield was attributed to a high content of ash and carbohydrates, suggesting that further investigations are needed on different strategies for for production of biocrude oil by HTL from low-grade algal blooms.

Acknowledgements This work was financially supported by the Chinese Universities Scientific Fund (2015SYL004). The authors thank Dianchi
Algae-Water Separation Station for assisting in the harvest of algal samples, Jamison Watson (University of Illinois at Urbana-Champaign) for helpful suggestions that improved the manuscript.

Compliance with ethics guidelines Ruixia Shen, Chunyan Tian, Zhidan Liu, Yuanhui Zhang, Baoming Li, Haifeng Lu, and Na Duan declare that they have no conflict of interest or financial conflicts to disclose.

This article does not contain any studies with human or animal subjects performed by any of the authors.

\section{References}

1. Smolders A J P, Lamers L P M, Lucassen E C H E, Van Der Velde G, Roelofs J G M. Internal eutrophication: how it works and what to do about it - a review. Chemistry and Ecology, 2006, 22(2): 93-111

2. Wen D H, Bai Y H, Shi Q, Li Z X, Sun Q H, Sun R H, Feng C P, Tang X Y. Bacterial diversity in the polluted water of the Dianchi 
Lakeshore in China. Annals of Microbiology, 2012, 62(2): 715-723

3. Catherine Q, Susanna W, Isidora E S, Mark H, Aurélie V, JeanFrançois H. A review of current knowledge on toxic benthic freshwater cyanobacteria-ecology, toxin production and risk management. Water Research, 2013, 47(15): 5464-5479

4. Tian C Y, Li B M, Liu Z D, Zhang Y H, Lu H F. Hydrothermal liquefaction for algal biorefinery: a critical review. Renewable \& Sustainable Energy Reviews, 2014, 38: 933-950

5. Gouveia L. Microalgae as a Feedstock for Biofuels. London: Springer, 2011.

6. Gupta V, Ratha S K, Sood A, Chaudhary V, Prasanna R. New insights into the biodiversity and applications of cyanobacteria (blue-green algae)-Prospects and challenges. Algal Research, 2013, 2(2): 79-97

7. Li H, Liu Z, Zhang Y, Li B, Lu H, Duan N, Liu M, Zhu Z, Si B. Conversion efficiency and oil quality of low-lipid high-protein and high-lipid low-protein microalgae via hydrothermal liquefaction. Bioresource Technology, 2014, 154: 322-329

8. Yu G, Zhang Y H, Schideman L, Funk T, Wang Z C. Distributions of carbon and nitrogen in the products from hydrothermal liquefaction of low-lipid microalgae. Energy \& Environmental Science, 2011, 4(11): 4587-4595

9. Biller P, Ross A B. Potential yields and properties of oil from the hydrothermal liquefaction of microalgae with different biochemical content. Bioresource Technology, 2011, 102(1): 215-225

10. Valdez P J, Tocco V J, Savage P E. A general kinetic model for the hydrothermal liquefaction of microalgae. Bioresource Technology, 2014, 163: 123-127

11. Richmond A. Handbook of microalgal culture: biotechnology and applied phycology. Oxford: Blackwell Publishing, 2004

12. Andersson A F, Riemann L, Bertilsson S. Pyrosequencing reveals contrasting seasonal dynamics of taxa within Baltic Sea bacterioplankton communities. The ISME Journal, 2010, 4(2): 171-181

13. Xing W, Huang W M, Liu Y D, Li D H, Shen Y W, Li G B. Environmental mechanism of change in cyanobacterial species composition in the northeastern part of Lake Dianchi (China). Fresenius Environmental Bulletin, 2007, 16(1): 82-90

14. Anthony R J, Ellis J T, Sathish A, Rahman A, Miller C D, Sims R C. Effect of coagulant/flocculants on bioproducts from microalgae. Bioresource Technology, 2013, 149: 65-70

15. Sheng H, Liu H, Wang C Y, Guo H C, Liu Y, Yang Y H. Analysis of cyanobacteria bloom in the Waihai part of Dianchi Lake, China. Ecological Informatics, 2012, 10: 37-48

16. Zhu L, Wu C Q, Yao Y J, Zhang Y J. Spatial and temporal distribution variation and meteorological factors analyzing of algal blooms based on HJ-1 satellites in Lake Dianchi, China, 2009. IEEE, 2010: 2769-2772

17. González López C V, García M C, Fernández F G A, Bustos C S, Chisti Y, Sevilla J M F. Protein measurements of microalgal and cyanobacterial biomass. Bioresource Technology, 2010, 101(19): 7587-7591

18. Tian C, Liu Z, Zhang Y, Li B, Cao W, Lu H, Duan N, Zhang L, Zhang T. Hydrothermal liquefaction of harvested high-ash low-lipid algal biomass from Dianchi Lake: effects of operational parameters and relations of products. Bioresource Technology, 2015, 184: 336343
19. Nübel U, Garcia-Pichel F, Muyzer G. PCR primers to amplify $16 \mathrm{~S}$ rRNA genes from cyanobacteria. Applied and Environmental Microbiology, 1997, 63(8): 3327-3332

20. Singleton D R, Jones M D, Richardson S D, Aitken M D. Pyrosequence analyses of bacterial communities during simulated in situ bioremediation of polycyclic aromatic hydrocarbon-contaminated soil. Applied Microbiology and Biotechnology, 2013, 97(18): 8381-8391

21. Sun F, Pei H Y, Hu W R, Li X Q, Ma C X, Pei R T. The cell damage of Microcystis aeruginosa in PACl coagulation and floc storage processes. Separation and Purification Technology, 2013, 115: 123128

22. Hu Z Q, Zheng Y, Yan F, Xiao B, Liu S M. Bio-oil production through pyrolysis of blue-green algae blooms (BGAB): product distribution and bio-oil characterization. Energy, 2013, 52: 119125

23. Anderson D M, Glibert P M, Burkholder J M. Harmful algal blooms and eutrophication: nutrient sources, composition, and consequences. Estuaries, 2002, 25(4): 704-726

24. Khan F A, Ansari A A. Eutrophication: an ecological vision. Botanical Review, 2005, 71(4): 449-482

25. Wang K, Colica G, De Philippis R, Liu Y, Li D. Biosorption of copper by cyanobacterial bloom-derived biomass harvested from the eutrophic Lake Dianchi in China. Current Microbiology, 2010, 61 (4): 340-345

26. Liu Z H, Liu X H, He B, Nie J F, Peng J Y, Zhao L. Spatio-temporal change of water chemical elements in Lake Dianchi, China. Water and Environmental Journal, 2009, 23(3): 235-244

27. Wu L, Feng W S. Temporal heterogeneity of plankton community in Lake Dianchi and its relation to environmental factors. Journal of Freshwater Ecology, 2012, 27(2): 229-241

28. Bao Z X. The temporal and spatial variation of aquatic phytoplankton and microcystin in Dianchi Lake and the removal of microcvstin with bacteria. Dissertation for the Master Degree. Kunming: Yunnan University, 2012 (in Chinese)

29. Davis T W, Berry D L, Boyer G L, Gobler C J. The effects of temperature and nutrients on the growth and dynamics of toxic and non-toxic strains of Microcystis during cyanobacteria blooms. Harmful Algae, 2009, 8(5): 715-725

30. Zhou Y, Schideman L, Yu G, Zhang Y H. A synergistic combination of algal wastewater treatment and hydrothermal biofuel production maximized by nutrient and carbon recycling. Energy \& Environmental Science, 2013, 6(12): 3765-3779

31. Xue C, Liu X, Qi C, Wei H, Song X, Liu Y, Hao B. Element geochemical characteristics of modern sediments in the Dianchi Lake, Kunming, and their environmental significance. Acta Petrologica Et Mneralogica, 2007, 26(6): 582-590 (in Chinese)

32. Yuan Z, Taoran S, Yan Z, Tao Y. Spatial distribution and risk assessment of heavy metals in sediments from a hypertrophic plateau lake Dianchi, China. Environmental Monitoring and Assessment, 2014, 186(2): 1219-1234

33. Paerl H W, Fulton R S 3rd, Moisander P H, Dyble J. Harmful freshwater algal blooms, with an emphasis on cyanobacteria. The Scientific World Journal, 2001, 1: 76-113

34. Takaara T, Sano D, Konno H, Omura T. Cellular proteins of Microcystis aeruginosa inhibiting coagulation with polyaluminum 
chloride. Water Research, 2007, 41(8): 1653-1658

35. Huang W, Bi Y, Hu Z. Effects of fertilizer-urea on growth, photosynthetic activity and microcystins production of Microcystis aeruginosa isolated from Dianchi Lake. Bulletin of Environmental Contamination and Toxicology, 2014, 92(5): 514-519
36. De Philippis R, Colica G, Micheletti E. Exopolysaccharideproducing cyanobacteria in heavy metal removal from water: molecular basis and practical applicability of the biosorption process. Applied Microbiology and Biotechnology, 2011, 92(4): 697-708 